\title{
Coronary Flow in Patients with Three-Vessel Disease: Simulated Hemodynamic Variables in relation to Angiographically Assessed Collaterality and History of Myocardial Infarction
}

\author{
Issam Abouliatim, ${ }^{1,2}$ Majid Harmouche, ${ }^{1,2}$ Agnès Drochon, ${ }^{3}$ Mahmoud Maasrani, ${ }^{4}$ \\ Hervé Corbineau, ${ }^{1,2}$ and Jean-Philippe Verhoye ${ }^{1,2}$ \\ ${ }^{1}$ Department of Thoracic and Cardiovascular Surgery, Rennes Hospital Center, 35000 Rennes, France \\ ${ }^{2}$ Research Unit INSERM U642, Rennes 1, France \\ ${ }^{3}$ UMR CNRS 6600, University of Technology of Compiègne, 60200 Compiègne, France \\ ${ }^{4}$ Faculty of Sciences, Lebanese University, Tripoli, Lebanon
}

Correspondence should be addressed to Agnès Drochon, agnes.drochon@utc.fr

Received 11 November 2011; Accepted 18 December 2011

Academic Editor: I. Sipahi

Copyright (C) 2011 Issam Abouliatim et al. This is an open access article distributed under the Creative Commons Attribution License, which permits unrestricted use, distribution, and reproduction in any medium, provided the original work is properly cited.

We study patients with stenoses of the left main coronary artery (LMCA), left anterior descending artery (LAD), and left circumflex branch (LCx) and with chronic occlusion of the right coronary artery (RCA), undergoing off-pump coronary surgery. An analog electrical model is used to provide quantitative estimations of the distribution of flows and pressures across the coronary network (in the stenosed native arteries, the collateral branches, the capillary areas, and so forth). The present paper demonstrates that the clinical information collected for the 10 patients included in the study (Rentrop score, history of myocardial infarction, left ventricular ejection fraction (LVEF)) are well correlated with the predicted hydrodynamic data. Patients with a good collaterality (Rentrop score $=3$ ) or patients without anterior myocardial infarction have (i) less severe stenoses on the LMCA, (ii) lower microvascular resistances, (iii) higher grafts flow rates when the revascularization is performed, (iv) higher collateral flow rates towards the territory of the occluded artery, (v) better perfusion of this area, and (vi) better total perfusion of the heart.

\section{Introduction}

In this work, we study patients with stenoses of the left main coronary artery (LMCA), left anterior descending artery (LAD), and left circumflex branch (LCx) and with chronic occlusion of the right coronary artery (RCA), undergoing off-pump coronary surgery. In this clinical situation, some quantities of interest, for example, the collateral flows to the occluded artery, are difficult to ascertain via preoperative measurements. That is why we proposed in previously published papers [1-3] a model of the coronary circulation based on hydraulic/electric analogy. This model provides quantitative estimations of the distribution of flows and pressures across the coronary network (in the stenosed native arteries, the collateral branches, the capillary areas, and so forth). Complete simulation results have been published for 10 patients in Maasrani et al. [3]. The objective of the present paper is to study how the clinical information collected for these patients (Rentrop score, history of myocardial infarction, left ventricular ejection fraction (LVEF)) can be correlated with the predicted hydrodynamic data. Such relationships between qualitative or medical observations and quantitative flows and pressures evaluations are lacking at the time, and it is hoped that this study will augment the surgeons' professional experience.

\section{Materials and Methods}

2.1. Clinical Measurements for Each Patient. Informed, signed consent was obtained from the patients before participating in the study.

The reductions in diameter and area of the stenosed arteries were estimated from angiographic observations, before 


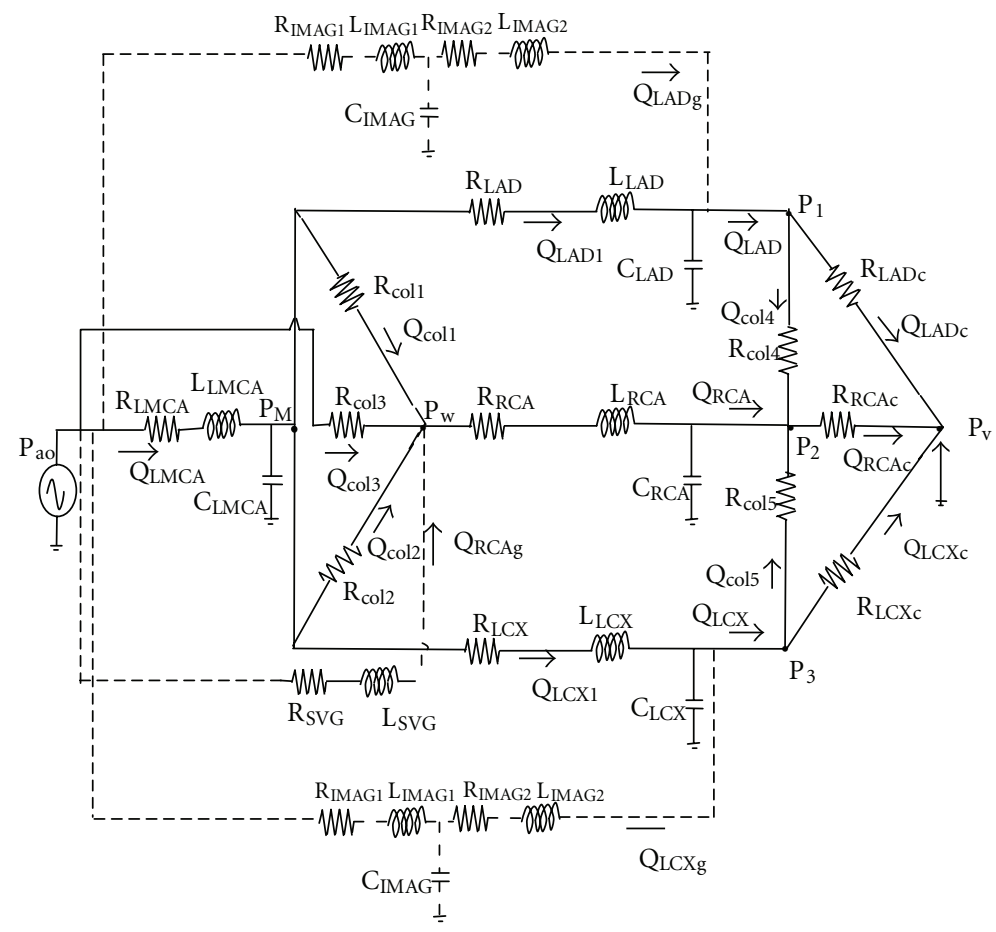

FIGURE 1: Analog electrical model for the coronary network in case of stenoses on the LMCA, LAD, LCx, and chronic occlusion of the RCA $[2,3]$. The grafts are represented with dotted lines.

surgery. Collateral filling of the RCA was scored using the Rentrop classification [4]: $0=$ no filling; $1=$ filling of the distal branches without visualization of its epicardial segment; $2=$ partial filling of the epicardial segment; $3=$ complete filling of the epicardial segment via collateral vessels.

The off-pump coronary surgical procedure has been described previously [5]. The RCA is first revascularized via a saphenous vein graft. Two series of measurements are performed: $P_{\text {ao }}$ (aortic pressure), $P_{v}$ (central venous pressure), $P_{w}$ (pressure distal to the RCA occlusion), with the right graft clamped (0G), and $P_{\mathrm{ao}}, P_{v}, Q_{\mathrm{RCAg}}$ (flow rate in the RCA graft) with the right graft opened $(1 \mathrm{G})$. The left coronary arteries are then revascularized via the internal thoracic arteries. Two additional series of measurements are performed: $P_{\mathrm{ao}}, P_{v}, P_{w}$, $Q_{\text {LADg }}$ and $Q_{\text {LCxg }}$ (flow rates in the LAD and LCx grafts) with the right graft clamped (2G), and $P_{\mathrm{ao}}, P_{v}, Q_{\mathrm{LADg}}, Q_{\mathrm{LCxg}}$, and $Q_{\mathrm{RCAg}}$ with the right graft opened $(3 \mathrm{G})$.

2.2. Simulations. The electrical analog model was first presented in Maasrani et al. [1]. It has then been modified in order to include possible stenosis on the LMCA and to take into account variable stenosis coefficients on all left branches $[2,3]$. It is shown in Figure 1.

Since the resistive effects are preponderant for small diameter vessels, in this model, the capillaries are represented by their hydraulic resistances $\left(R_{\mathrm{LADc}}, R_{\mathrm{LCXc}}\right.$, and $R_{\mathrm{RCAc}}$ are the resistances of the capillaries vascularized by the LAD, LCx, and RCA arteries, resp.). The blood flow rates across the LAD, LCx, and RCA capillaries are denoted by $Q_{\mathrm{LADc}}$, $Q_{\mathrm{LCX}}$, and $Q_{\mathrm{RCAc}}$, respectively. The collateral vessels are also represented only by their resistances $R_{\text {coli }}, i=1-5$. $Q_{\text {coll }}$ and $Q_{\text {col4 }}$ are the collateral flow rates from LAD towards RCA (before and after LAD stenoses, resp.), $Q_{\mathrm{col} 2}$ and $Q_{\mathrm{col} 5}$ are the collateral flow rates from LCx (before and after LCx stenoses, resp.) and $Q_{\mathrm{col} 3}$ is the collateral flow rate from the aorta towards the RCA. Due to the difficulty of determining the exact characteristics of the collateral pathways, it was assumed that all the collateral resistances are the same [1]: $R_{\mathrm{col} 1}=R_{\mathrm{col} 2}=R_{\mathrm{col} 3}=R_{\mathrm{col} 4}=R_{\mathrm{col} 5}=R_{\mathrm{col}}$. The microvascular resistances $\left(R_{\mathrm{LADc}}, R_{\mathrm{LCxc}}, R_{\mathrm{RCAc}}, R_{\mathrm{col}}\right)$ are patient specific. Their determination is performed using the clinical data measured during off-pump surgery (Section 2.1), as explained in Maasrani et al. [2]. The other parameters of the model (resistances, inductances, and compliances of the left branches, of the RCA (distal to the thrombosis) and of the grafts) are taken from the literature $[6,7]$. The influence of the stenoses on the LMCA, LAD and LCx is also described according to Wang et al. [7]. The input of the model is the aortic pressure wave, $P_{\mathrm{ao}}(t)$, measured for each patient and each situation $(0 \mathrm{G}, 1 \mathrm{G}, 2 \mathrm{G}, 3 \mathrm{G})$. The simulations are performed with the Matlab Simulink program. The calculated flows and pressures are time dependent, but, since the influence of ventricular contraction upon coronary vascular bed resistance is not taken into account in our simulations at the time, we focus on average cardiac cycle values. Besides, this is consistent with the fact that the collected clinical data are also average cardiac cycle values.

2.3. Statistical Analysis. Our study includes only a small number of patients $(n=10)$. Consequently, no reliable 
TABle 1: Area reductions on the left branches, history of myocardial infarction, and LVEF (\%): (a) Patients with Rentrop 3, (b) Patients with Rentrop 1 and 2. No. Pat. in [3]: number of the patient in Maasrani et al. [3].

(a)

\begin{tabular}{|c|c|c|c|c|c|c|}
\hline No. Pat. in [3] & $\begin{array}{c}\text { Area reduc. LMCA } \\
(\%)\end{array}$ & $\begin{array}{c}\text { Area reduc. LAD } \\
(\%)\end{array}$ & $\begin{array}{c}\text { Area reduc. LCx } \\
(\%)\end{array}$ & $\begin{array}{l}\text { Mean reduc. all left } \\
\text { branches }(\%)\end{array}$ & AMI? & LVEF (\%) \\
\hline 1 & 26 & 100 & 90 & 72 & No & 60 \\
\hline 3 & 91.6 & 84.8 & 95.6 & 90.67 & No & 45 \\
\hline 4 & 19 & 86 & 97 & 67.33 & No & 67 \\
\hline 5 & 20 & 88 & 92 & 66.67 & No & 66 \\
\hline 7 & 80 & 0 & 85 & 55 & Yes & 30 \\
\hline Mean $\pm \sigma \mathrm{R} 3$ group & $47.32 \pm 35.47$ & $71.76 \pm 40.57$ & $91.92 \pm 4.77$ & $70.33 \pm 12.98$ & & $53.6 \pm 15.85$ \\
\hline
\end{tabular}

(b)

\begin{tabular}{lcccccc}
\hline No. Pat. in [3] & $\begin{array}{c}\text { Area reduc. LMCA } \\
(\%)\end{array}$ & $\begin{array}{c}\text { Area reduc. LAD } \\
(\%)\end{array}$ & $\begin{array}{c}\text { Area reduc. LCx } \\
(\%)\end{array}$ & $\begin{array}{c}\text { Mean reduc. all left } \\
\text { branches }(\%)\end{array}$ & AMI? & LVEF (\%) \\
\hline 2 & 46 & 89 & 95 & 76.67 & Yes & 57 \\
6 & 85 & 94 & 82 & 87 & No & 46 \\
8 & 87 & 70 & 90 & 82.33 & Yes & 60 \\
9 & 83 & 78 & 0 & 53.67 & No & 60 \\
10 & 75 & 93 & 0 & 56 & Yes & 30 \\
Mean $\pm \sigma$ R1 and 2 group & $75.2 \pm 16.95$ & $84.8 \pm 10.43$ & $53.4 \pm 48.97$ & $71.13 \pm 15.34$ & $50.6 \pm 12.88$ \\
\hline
\end{tabular}

statistical tests can be presented. The results are expressed as mean values \pm standard deviation.

\section{Results}

The clinical measurements and the results of the simulations for the 10 patients published in Maasrani et al. [3] are analyzed according to two different classifications of the patients: (i) in Section 3.1, group of patients with Rentrop Score $=3$ ("R3" group) versus group of patients with Rentrop Score $=1$ or 2 ("R1 and 2" group) and (ii) in Section 3.2, group of patients with an anterior myocardial infarction ("AMI" group) versus group of patients with no-AMI ("NoAMI" group). For each group of patients, the measured area reductions on the left branches, the calculated capillary and collateral resistances, the measured flow rates in the grafts, the predicted collateral flow rates, the predicted perfusion of the right territory, and total coronary perfusion are analyzed and compared.

3.1. Classification: "Rentrop 3" versus "Rentrop 1 and 2". According to the definition of the Rentrop Score, patients with Rentrop 3 are expected to have a more efficient collaterality than patients with Rentrop Score one or two $[8,9]$.

3.1.1. Severity of the Coronary Disease. The clinical data for our ten patients are presented in Tables 1(a) and 1(b). The "mean reduction on all left branches" is defined as (area reduction on LMCA + area reduction on LAD + area reduction on $\mathrm{LCx}) / 3$.

Lesions on LMCA are less severe in the "R3" group: $47.32 \% \pm 35.47$ versus $75.2 \% \pm 16.95$ in the "R1 and 2 " group. In the absence of the left grafts, a less obstructed LMCA will facilitate the LAD and LCx flows, and consequently, the collateral flows.

If one considers only the patients who have lesions on the LAD or on the LCx artery, no significant difference between the two groups can be demonstrated: mean value for the patients who have lesions on the LAD branch in the "R3" group $=(100+84.8+86+88) / 4=89.7 \% \pm 7.0$, compared to the mean area reduction of the LAD branch in the "R1 and 2" group $(84.8 \% \pm 10.43)$, and mean value for the patients who have lesions on the LCx branch in the "R1 and 2" group = $(95+82+90) / 3=89 \% \pm 6.56$, compared to the mean area reduction of the LCx branch in the "R3" group $(91.92 \% \pm$ 4.77).

Mean reductions of area for all left branches together are similar in the two groups: $70.33 \% \pm 12.98$ for the "R3" group and $71.13 \% \pm 15.34$ for the "R1 and 2" group.

A majority of patients of the "R3" group did not have an AMI, except Patient 7. On the contrary, Patients 6 and 9 have a Rentrop Score $=1$ or 2 and did not have an AMI. Patients with better collateral flow grades were more likely to have higher LVEF. This bears out similar observations by previous authors $[9,10]$.

3.1.2. Capillary and Collateral Resistances. The values of the calculated capillary and collateral resistances for the 10 patients are presented in Tables 2(a) and 2(b). The mean capillary resistance, $R_{\text {capmean }}$, is defined as $R_{\text {capmean }}=\left(R_{\mathrm{LADc}}+\right.$ $\left.R_{\mathrm{LCxc}}+R_{\mathrm{RCAc}}\right) / 3$.

Except for the $R_{\mathrm{LCxc}}$ value (i.e., comparable in the "R3" and "R1 and 2" groups), all the other microvascular resistances are significantly lower in the "R3" group. The proportion between the right capillary resistance, $R_{\mathrm{RCAc}}$, and the 
TABLe 2: Capillary and collateral resistances values ( $\mathrm{mmHg} \cdot \mathrm{s} / \mathrm{mL}$ ): (a) Patients with Rentrop 3, (b) Patients with Rentrop 1 and 2.

(a)

\begin{tabular}{lcccccc}
\hline No. Pat. in [3] & $R_{\mathrm{LADc}}$ & $R_{\mathrm{LCxc}}$ & $R_{\mathrm{RCAc}}$ & $R_{\mathrm{col}}$ & $R_{\text {capmean }}$ & $R_{\mathrm{RCAc}} / R_{\mathrm{capmean}}$ \\
\hline 1 & 83.3 & 207.9 & 54.1 & 160 & 115.1 & 0.47 \\
3 & 213 & 94.2 & 62.8 & 350 & 123.33 & 0.51 \\
4 & 47.5 & 119.1 & 147.2 & 565 & 205 & 104.6 \\
5 & 175.3 & 68.7 & 56.1 & 650 & 81.53 & 0.56 \\
7 & 50.2 & 118.4 & 76 & $386 \pm 216.14$ & $104.92 \pm 15.92$ & $0.77 \pm 0.4$ \\
\hline
\end{tabular}

(b)

\begin{tabular}{|c|c|c|c|c|c|c|}
\hline No. Pat. in [3] & $R_{\mathrm{LADc}}$ & $R_{\mathrm{LCxc}}$ & $R_{\mathrm{RCAC}}$ & $R_{\mathrm{col}}$ & $R_{\text {capmean }}$ & $R_{\mathrm{RCAC}} / R_{\text {capmean }}$ \\
\hline 2 & 174.6 & 210.9 & 96.9 & 430 & 160.8 & 0.6 \\
\hline 6 & 240.4 & 135.5 & 117.6 & 1055 & 164.5 & 0.71 \\
\hline 8 & 77.6 & 196 & 347.6 & 970 & 207.06 & 1.68 \\
\hline 9 & 374.8 & 33.7 & 80.7 & 420 & 163.07 & 0.49 \\
\hline 10 & 155.9 & 62.1 & 213.8 & 405 & 143.93 & 1.485 \\
\hline Mean $\pm \sigma \mathrm{R} 1$ and 2 group & $204.66 \pm 111.41$ & $127.64 \pm 78.72$ & $171.32 \pm 111.26$ & $656 \pm 326.94$ & $167.87 \pm 23.42$ & $0.993 \pm 0.55$ \\
\hline
\end{tabular}

other capillary resistances, $R_{\text {capmean }}$, is also lower in the "R3" group. This seems quite logical: lower collateral and right capillary resistances will facilitate the collateral flows [11, 12].

Looking patient by patient, it can be noticed from the data of Tables 1(a), 1(b), 2(a), and 2(b) that the less severe mean artery lesions (mean reduction all left branches) are generally associated with lower microvascular resistances. It can be also noticed that low distal capillary resistances are obtained for the nonstenosed arteries. Such a trend was previously demonstrated by Chamuleau et al. [13]. These authors found an association between coronary lesion severity and the resistance of the downstream microcirculation assessed by intracoronary-derived pressure and Doppler flow velocity measurement. They also demonstrated that minimal microvascular resistance is higher distal to hemodynamically significant stenosis compared with vessels without stenosis in the same patient. This relationship is not so evident in our study because of the existence of multiple artery lesions and of the confounding effect of collateral flow.

3.1.3. Measured Flow Rates in the Grafts, in the Case (2G) (Right Graft Clamped) and (3G) (Right Graft Unclamped). These data are presented in Tables 3(a) and 3(b).

The flow rates in the grafts are much higher in the "R3" group, probably because the microvascular resistances are smaller. As demonstrated by many authors [14-18], the status of the distal supplied territory influences the flow in the graft.

3.1.4. Simulated Collateral Flow Rates, in the Cases (OG) and $(2 G)$. The collateral flow rates in the case (0G) (resp., $(2 G)$ ) are presented in Tables 4(a) and 4(b) (resp., Tables 5(a) and 5(b)). $Q_{\text {coltotal }}$ represents the sum of all collateral flows $\left(Q_{\mathrm{col} 1}+Q_{\mathrm{col} 2}+Q_{\mathrm{col} 3}+Q_{\mathrm{col} 4}+Q_{\mathrm{col} 5}\right)$. By construction of our model (Figure 1), $P_{M}-P_{w}=R_{\mathrm{col} 1} * Q_{\mathrm{col} 1}=R_{\mathrm{col} 2} * Q_{\mathrm{col} 2}$. Since $R_{\mathrm{col} 1}=R_{\mathrm{col} 2}, Q_{\mathrm{col} 1}=Q_{\mathrm{col} 2}$.
In the case $(0 \mathrm{G})$, the predicted collateral flow rates, $Q_{\text {coll }}$, $Q_{\text {col2 }}, Q_{\text {col3 }}$, and $Q_{\text {coltotal }}$, are higher in the "R3" group. This is related to less severe LMCA stenoses and lower collateral and right capillary resistances for the patients of this group. Some negative collateral flow rates (from the right branch to a left branch) may occur if one of the left branches has a very severe stenosis (e.g., this is the case of Patient 1 whose LAD is almost totally obstructed). Such an inversion of collateral flow has previously been shown in the literature, due to an inversion of the pressure gradient across the collateral network [19]. Although the influence of collateral flows remains moderate, it may substantially influence the occurrence of ischemia in the right distal territory. Other studies also reached the same conclusion and established that angiographical presence of collaterals is a clinically relevant prognostic factor $[8,9,20]$.

In the case $(2 \mathrm{G})$, higher collateral flow rates are also found for the patients of the group "R3." As previously shown [1-3], the left grafts do not really improve the collateral flows (comparison of the case $(2 \mathrm{G})$ with the pathological situation $(0 G))$.

3.1.5. Simulated Flow Rates towards the Right Capillary Area $Q_{\text {RCAc. }}$ These flow rates are presented in Tables 6(a) and 6(b), for the four revascularization situations considered in this study.

Patients of the group "R3" show a quite better perfusion of the right-sided myocardial territories, in all cases, due to lower $R_{\text {col }}$ and $R_{\text {RCAc }}$ resistances. As explained in Section 3.1.4, the presence of the left grafts does not induce a significant improvement of the perfusion of the right territory (situation (2G) compared to situation (0G)). Such an improvement is obtained when the right graft is operating.

3.1.6. Simulated Total Coronary Flow Rate $Q_{t} . Q_{t}$ represents the sum of the flow rates in the LAD branch, LCx and RCA branch. Its values are given in Tables $7(\mathrm{a})$ and $7(\mathrm{~b})$, for 
TABle 3: Measured flow rates (mL/min) in the grafts, in the case (2G) and (3G): (a) Patients with Rentrop 3, (b) Patients with Rentrop 1 and 2 .

(a)

\begin{tabular}{|c|c|c|c|c|c|}
\hline No. Pat. in [3] & $Q_{\text {LADg }}(2 G)$ & $Q_{\mathrm{LCxg}}(2 \mathrm{G})$ & $Q_{\text {LADg }}(3 G)$ & $Q_{\text {LCxg }}(3 G)$ & $Q_{\mathrm{RCAg}}(3 \mathrm{G})$ \\
\hline 1 & 34 & 27 & 40 & 14 & 66 \\
\hline 3 & 22 & 48 & 19 & 45 & 74 \\
\hline 4 & 59 & 40 & 57 & 30 & 26 \\
\hline 5 & 24 & 56 & 18 & 46 & 69 \\
\hline 7 & 28 & 43 & 28 & 29 & 51 \\
\hline Mean $\pm \sigma$ R3 group & $33.4 \pm 15.03$ & $42.8 \pm 10.71$ & $32.4 \pm 16.35$ & $32.8 \pm 13.22$ & $57.2 \pm 19.43$ \\
\hline
\end{tabular}

(b)

\begin{tabular}{|c|c|c|c|c|c|}
\hline No. Pat. in [3] & $Q_{\text {LADg }}(2 G)$ & $Q_{\mathrm{LCxg}}(2 \mathrm{G})$ & $Q_{\text {LADg }}(3 G)$ & $Q_{\mathrm{LCxg}}(3 \mathrm{G})$ & $Q_{\text {RCAg }}(3 G)$ \\
\hline 2 & 23 & 32 & 21 & 19 & 45 \\
\hline 6 & 11 & 12 & 14 & 18 & 30 \\
\hline 8 & 38 & 16 & 28 & 17 & 10 \\
\hline 9 & 24 & 60 & 23 & 45 & 51 \\
\hline 10 & 20 & 7 & 18 & 13 & 14 \\
\hline Mean $\pm \sigma \mathrm{R} 1$ and 2 group & $23.2 \pm 9.73$ & $25.4 \pm 21.49$ & $20.8 \pm 5.26$ & $22.4 \pm 12.84$ & $30 \pm 18.18$ \\
\hline
\end{tabular}

TABLe 4: Simulated collateral flow rates ( $\mathrm{mL} / \mathrm{min})$ in the case (0G): (a) Patients with Rentrop 3, (b) Patients with Rentrop 1 and 2.

(a)

\begin{tabular}{|c|c|c|c|c|c|}
\hline No. Pat. in [3] & $Q_{\text {coll }}$ & $Q_{\mathrm{col} 3}$ & $Q_{\mathrm{col} 4}$ & $Q_{\mathrm{col} 5}$ & $Q_{\text {coltotal }}$ \\
\hline 1 & 10.6 & 10.7 & -7.0 & 6.6 & 31.5 \\
\hline 3 & 6.2 & 8.9 & 4.9 & -0.4 & 25.8 \\
\hline 4 & 3.9 & 3.9 & 1.5 & -1.2 & 12 \\
\hline 5 & 10.4 & 10.5 & 6.2 & 1.5 & 39 \\
\hline 7 & 3.6 & 4.3 & 3.6 & 3.0 & 18.1 \\
\hline Mean $\pm \sigma$ R3 group & $6.94 \pm 3.4$ & $7.66 \pm 3.33$ & $1.84 \pm 5.24$ & $1.9 \pm 3.1$ & $25.28 \pm 10.67$ \\
\hline
\end{tabular}

(b)

\begin{tabular}{lccccc}
\hline No. Pat. in [3] & $Q_{\text {col1 }}$ & $Q_{\text {col3 }}$ & $Q_{\text {col4 }}$ & $Q_{\text {col5 }}$ & $Q_{\text {coltotal }}$ \\
\hline 2 & 5.6 & 5.7 & 3.3 & 1.8 & 22 \\
6 & 2.5 & 2.8 & 1.2 & 2.3 & 11.2 \\
8 & 1.4 & 1.9 & 3.1 & 3.9 & 6.8 \\
9 & 3.4 & 4.6 & -0.4 & 2.4 & 9.8 \\
10 & 2.5 & 2.8 & $1.66 \pm 1.54$ & $2.14 \pm 0.88$ & $13.52 \pm 6.22$ \\
Mean $\pm \sigma$ R1 and 2 group & $3.08 \pm 1.58$ & $3.56 \pm 1.55$ & &
\end{tabular}

the four revascularization situations ((0G), (1G), (2G), and $(3 \mathrm{G})$ ).

The results obtained for the total coronary flow, $Q_{t}$, are quite consistent with the other results of this paper: patients of the group "R3" have higher collateral flow rates, higher grafts flow rates, lower microvascular resistances, and so forth. Consequently, the values of $Q_{t}$ for these patients are also higher than for the patients of the "R1 and 2" group. The results of Tables 7 (a) and 7(b) are also consistent with the results of theoretical simulations that we previously published to see the impact of capillary and collateral resistances on the total coronary flow rate $Q_{t}$ (see [1, Figures 5 and 6]). These simulations have shown that
$Q_{t}$ is improved when the capillary resistances and/or the collateral resistances are decreased.

3.2. Classification "AMI" versus "No-AMI". The objective of this classification of the patients was to test if the history of myocardial infarction was associated with a less efficient collaterality and impaired microvascular resistances. Indeed, it is well accepted that destruction of the morphologic integrity and scar formation of the myocardium as caused by myocardial infarction negatively affects the coronary microcirculation. Although the presence of microvascular injury can be assessed with several invasive and noninvasive techniques [21], this assessment remains challenging. 
Table 5: Simulated collateral flow rates ( $\mathrm{mL} / \mathrm{min})$ in the case (2G): (a) Patients with Rentrop 3, (b) Patients with Rentrop 1 and 2.

(a)

\begin{tabular}{|c|c|c|c|c|c|}
\hline No. Pat. in [3] & $Q_{\text {coll }}$ & $Q_{\mathrm{col} 3}$ & $Q_{\text {col } 4}$ & $Q_{\text {col5 }}$ & $Q_{\text {coltotal }}$ \\
\hline 1 & 7.4 & 7.4 & 5.8 & 6.7 & 34.7 \\
\hline 3 & 6.2 & 6.9 & 6.3 & 5.9 & 31.5 \\
\hline 4 & 2.8 & 2.8 & 2.2 & 2.5 & 13.1 \\
\hline 5 & 7.4 & 7.4 & 6.7 & 5.9 & 34.8 \\
\hline 7 & 4.1 & 4.4 & 4.0 & 4.0 & 20.6 \\
\hline Mean $\pm \sigma$ R3 group & $5.58 \pm 2.06$ & $5.78 \pm 2.08$ & $5.0 \pm 1.87$ & $5.0 \pm 1.71$ & $26.94 \pm 9.68$ \\
\hline
\end{tabular}

(b)

\begin{tabular}{|c|c|c|c|c|c|}
\hline No. Pat. in [3] & $Q_{\text {coll }}$ & $Q_{\mathrm{col} 3}$ & $Q_{\text {col4 }}$ & $Q_{\text {col5 }}$ & $Q_{\text {coltotal }}$ \\
\hline 2 & 4.6 & 4.6 & 4.2 & 4.3 & 22.3 \\
\hline 6 & 2.3 & 2.4 & 2.3 & 2.2 & 11.5 \\
\hline 8 & 1.3 & 1.5 & 1.2 & 1.3 & 6.6 \\
\hline 9 & 3.7 & 4.3 & 3.9 & 3.7 & 19.3 \\
\hline 10 & 2.1 & 2.4 & 2.0 & 2.1 & 10.7 \\
\hline Mean $\pm \sigma \mathrm{R} 1$ and 2 group & $2.8 \pm 1.33$ & $3.04 \pm 1.34$ & $2.72 \pm 1.28$ & $2.72 \pm 1.24$ & $14.08 \pm 6.5$ \\
\hline
\end{tabular}

TABLE 6: Simulated flow rates towards the right capillary area, $Q_{\mathrm{RCAc}}(\mathrm{mL} / \mathrm{min})$ : (a) Patients with Rentrop 3, (b) Patients with Rentrop 1 and 2 .

(a)

\begin{tabular}{|c|c|c|c|c|}
\hline No. Pat. in [3] & $Q_{\mathrm{RCAc}}(0 \mathrm{G})$ & $Q_{\mathrm{RCAc}}(1 \mathrm{G})$ & $Q_{\mathrm{RCAc}}(2 \mathrm{G})$ & $Q_{\mathrm{RCAc}}(3 \mathrm{G})$ \\
\hline 1 & 31.5 & 70.3 & 34.6 & 66 \\
\hline 3 & 25.8 & 73.9 & 31.6 & 74 \\
\hline 4 & 11.9 & 28 & 13.2 & 26 \\
\hline 5 & 38.8 & 75.3 & 34.9 & 68.9 \\
\hline 7 & 18.1 & 53.4 & 20.7 & 51 \\
\hline Mean $\pm \sigma \mathrm{R} 3$ group & $25.22 \pm 10.63$ & $60.18 \pm 20.0$ & $27 \pm 9.64$ & $57.18 \pm 19.42$ \\
\hline
\end{tabular}

(b)

\begin{tabular}{|c|c|c|c|c|}
\hline No. Pat. in [3] & $Q_{\mathrm{RCAc}}(0 \mathrm{G})$ & $Q_{\mathrm{RCAc}}(1 \mathrm{G})$ & $Q_{\mathrm{RCAc}}(2 \mathrm{G})$ & $Q_{\mathrm{RCAc}}(3 \mathrm{G})$ \\
\hline 2 & 21.9 & 47.4 & 22.3 & 45 \\
\hline 6 & 11.3 & 30 & 11.4 & 30 \\
\hline 8 & 6.7 & 12.1 & 6.6 & 10 \\
\hline 9 & 17.7 & 41.4 & 19.3 & 51 \\
\hline 10 & 9.8 & 15.1 & 10.7 & 14 \\
\hline Mean $\pm \sigma \mathrm{R} 1$ and 2 group & $13.48 \pm 6.18$ & $29.2 \pm 15.59$ & $14.06 \pm 6.5$ & $30 \pm 18.18$ \\
\hline
\end{tabular}

The group of patients who had an AMI includes patients no. $2,7,8,10$ ( $n=4$ patients); the group of patients who did not have an AMI includes patients no. 1, 3, 4, 5, 6, and 9 ( $n=6$ patients). The detailed data for these patients have been already recalled in Section 3.1; consequently, only the mean values for the two groups are given here, for the sake of comparison.

3.2.1. Severity of the Coronary Disease. Table 8 presents the mean values of area reductions on the left branches, Rentrop scores and LVEF, for the "AMI" group compared to those of the "No-AMI" group.

Patients of the group "AMI" have more severe stenoses on the LMCA branch than patients of the group "no-AMI"
$(72 \% \pm 18$ versus $54.1 \% \pm 35.7)$. Considering the patients who have stenoses on the LAD and on the LCx branch, no significant differences appear in the mean severity of the stenoses between the two groups: mean area reduction for the patients who have stenoses on the LAD in the "AMI" group $=(89+70+93) / 3=84 \% \pm 12.3$ versus $88.47 \% \pm 7.65$ in the "No-AMI" group, and mean area reduction for the patients who have stenoses on the LCx in the "No-AMI" group $=(90+95.6+97+92+82) / 5=91.32 \% \pm 5.91$ versus $(95+85+90) / 3=90 \% \pm 5$ in the "AMI" group. Collaterality (Rentrop Score) is better for the group "No-AMI" and is associated with a less severe deterioration of the left ventricular ejection fraction. This result is quite consistent with that of Bexell et al. [22] who demonstrate a relationship between 
TAble 7: Simulated total coronary flow rates, $Q_{t}(\mathrm{~mL} / \mathrm{min})$ : (a) Patients with Rentrop 3, (b) Patients with Rentrop 1 and 2.

(a)

\begin{tabular}{lcccc}
\hline No. Pat. in [3] & $Q_{t}(0 \mathrm{G})$ & $Q_{t}(1 \mathrm{G})$ & $Q_{t}(2 \mathrm{G})$ & 82.3 \\
$Q_{t}(3 \mathrm{G})$ \\
3 & 51.9 & 102.2 & 94.5 & 122.9 \\
4 & 57.1 & 113.3 & 108.1 & 141.9 \\
5 & 75.8 & 98.7 & 100.2 & 129.4 \\
7 & 94.5 & 135.3 & 139.9 & 142.8 \\
Mean $\pm \sigma$ R3 group & 120.2 & 155.6 & $105 \pm 21.66$ & 156.4 \\
\hline
\end{tabular}

(b)

\begin{tabular}{lcccc}
\hline No. Pat. in [3] & $Q_{t}(0 \mathrm{G})$ & $Q_{t}(1 \mathrm{G})$ & $Q_{t}(2 \mathrm{G})$ & \\
\hline 2 & 55.9 & 84.5 & 64.1 & \\
6 & 49.3 & 62.5 & 54.2 & \\
6 & 67.7 & 74.2 & 70.2 & 69.4 \\
8 & 108.8 & 134.9 & 119.6 & 69.7 \\
9 & 71.7 & 78.5 & 81.2 & 775.7 \\
10 & $70.68 \pm 23.12$ & $86.92 \pm 28.0$ & $77.86 \pm 25.3$ & $96.76 \pm 44.88$ \\
\hline
\end{tabular}

TABLE 8: Area reductions on the left branches, Rentrop Score, and LVEF (\%): mean values of the group "AMI" compared to those of the group "No-AMI."

\begin{tabular}{|c|c|c|c|c|c|c|}
\hline & $\begin{array}{c}\text { Area reduc. LMCA } \\
(\%)\end{array}$ & $\begin{array}{c}\text { Area reduc. LAD } \\
(\%)\end{array}$ & $\begin{array}{c}\text { Area reduc. LCx } \\
(\%)\end{array}$ & $\begin{array}{l}\text { Mean reduc. all } \\
\text { left branches }\end{array}$ & Rentrop score & $\operatorname{LVEF}(\%)$ \\
\hline Mean $\pm \sigma$ “AMI” group & $72 \pm 18$ & $63 \pm 43.2$ & $67.5 \pm 45.2$ & $67.5 \pm 14.05$ & $2 \pm 0.8$ & $44.25 \pm 16.5$ \\
\hline Mean $\pm \sigma$ "No-AMI" group & $54.1 \pm 35.7$ & $88.47 \pm 7.65$ & $76.13 \pm 37.67$ & $72.89 \pm 13.84$ & $2.5 \pm 0.84$ & $57.33 \pm 9.63$ \\
\hline
\end{tabular}

coronary artery lesion severity, extent of collateralization, and importance of the microvascular damages.

3.2.2. Capillary and Collateral Resistances. The mean values of the capillary and collateral resistances are given in Table 9, for the "AMI" group, compared to those of the "No-AMI" group.

As expected, most of the microvascular resistances $\left(R_{\mathrm{LCxc}}\right.$, $R_{\mathrm{RCAc}}, R_{\text {col }}, R_{\text {capmean }}$ ) are lower in the group "No-AMI" than in the group "AMI." The proportion between the $R_{\mathrm{RCAc}}$ and the other capillary resistances, $R_{\mathrm{RCAc}} / R_{\text {capmean }}$, is also lower. It has been demonstrated by several authors that acute myocardial infarction can be associated with the presence of microvascular obstruction $[21,23]$, which would of course induce an increase in capillary vascular resistances. In a somewhat different study (balloon angioplasty in patients with one-vessel disease), Van Liebergen et al. [24] also found that the collateral resistance and the peripheral resistance of the recipient coronary artery are lower in the group of patients without ischemia compared to the group with ischemia. Unfortunately, their data are expressed in units that cannot be directly compared to ours.

We note that the mean value of $R_{\mathrm{LADc}}$ in the "AMI group" is influenced by Patient 7, who does not have any stenosis on the LAD branch, and who presents a low value of $R_{\mathrm{LADc}}$.

3.2.3. Measured Flow Rates in the Grafts, in the Case (2G) (Right Graft Clamped) and (3G) (Right Graft Unclamped). As shown in Table 10, there is no important difference in the LAD graft flow rates between the 2 groups ("AMI" and "NoAMI"). But there is a significative difference in the LCx graft flow rates: they are much higher in the "No-AMI" group $(40.5 \mathrm{~mL} / \mathrm{min} \pm 18.28$ in the case $(2 \mathrm{G})$ and $33 \mathrm{~mL} / \mathrm{min} \pm$ 14.5 in the case $(3 \mathrm{G}))$ than in the "AMI" group $(24.5 \mathrm{~mL} / \mathrm{min}$ \pm 16.1 in the case $(2 \mathrm{G})$ and $19.5 \mathrm{~mL} / \mathrm{min} \pm 6.8$ in the case $(3 G))$. The flow rates in the right graft are also much higher for the patients who did not have an AMI. As explained in Section 3.1.3, this could be related to the fact that the resistances of the distal perfused territories, $R_{\mathrm{LCxc}}$ and $R_{\mathrm{RCAc}}$, are lower for this group of patients. Spies et al. [15] also found that flow reserve is reduced in bypasses supplying infarcted myocardium, likely due to altered microcirculation.

3.2.4. Simulated Collateral Flow Rates, in the Cases (OG) and $(2 G)$. The mean values of the simulated collateral flow rates in the case (0G) (resp., (2G)) for the two groups of patients are presented in Table 11 (resp., Table 12).

As can be seen in Table 11, the collateral flows $Q_{\text {coll }}$ and $Q_{\text {col2 }}$ are higher for the patients of the "No-AMI" group. This may be related to the fact that patients of this group have less severe stenoses on the LMCA. The total collateral flows are also higher for these patients, which is consistent with the fact that their $R_{\mathrm{col}}$ and $R_{\mathrm{RCAc}}$ are lower than for the patients who had an AMI. Our data thus support the observation made by many authors (e.g., Levin [25]) that well-developed collaterals exert a beneficial effect on myocardial viability and 
TABLE 9: Capillary and collateral resistances values $(\mathrm{mmHg} \cdot \mathrm{s} / \mathrm{mL})$ : mean values of the group "AMI" compared to those of the group "NoAMI."

\begin{tabular}{|c|c|c|c|c|c|c|}
\hline & $R_{\mathrm{LADc}}$ & $R_{\mathrm{LCxc}}$ & $R_{\mathrm{RCAc}}$ & $R_{\mathrm{col}}$ & $R_{\text {capmean }}$ & $R_{\mathrm{RCAc}} / R_{\text {capmean }}$ \\
\hline Mean $\pm \sigma$ “AMI" group & $114.57 \pm 60.06$ & $146.85 \pm 69.55$ & $183.57 \pm 125.04$ & $613.75 \pm 261.77$ & $148.3 \pm 51.9$ & $1.17 \pm 0.49$ \\
\hline Mean $\pm \sigma$ "No-AMI" group & $189.05 \pm 117.58$ & $109.85 \pm 60.16$ & $86.42 \pm 38.0$ & $459.17 \pm 326.73$ & $128.44 \pm 28.56$ & $0.69 \pm 0.36$ \\
\hline
\end{tabular}

TABLE 10: Measured flow rates $(\mathrm{mL} / \mathrm{min})$ in the grafts, in the case $(2 \mathrm{G})$ and $(3 \mathrm{G})$ : mean values of the group "AMI" compared to those of the group "No-AMI."

\begin{tabular}{lccccc}
\hline & $Q_{\mathrm{LADg}}(2 \mathrm{G})$ & $Q_{\mathrm{LCxg}}(2 \mathrm{G})$ & $Q_{\mathrm{LADg}}(3 \mathrm{G})$ & $Q_{\mathrm{LCxg}}(3 \mathrm{G})$ & $Q_{\mathrm{RCAg}}(3 \mathrm{G})$ \\
\hline Mean $\pm \sigma$ "AMI" group & $27.25 \pm 7.89$ & $24.5 \pm 16.1$ & $23.75 \pm 5.06$ & $19.5 \pm 6.8$ & $30 \pm 21.0$ \\
Mean $\pm \sigma$ "No-AMI" group & $29 \pm 16.42$ & $40.5 \pm 18.28$ & $28.5 \pm 16.65$ & $33 \pm 14.5$ & $52.67 \pm 20.63$ \\
\hline
\end{tabular}

TABLE 11: Simulated collateral flow rates $(\mathrm{mL} / \mathrm{min})$ in the case $(0 \mathrm{G}):$ mean values of the group "AMI" compared to those of the group "No-AMI."

\begin{tabular}{|c|c|c|c|c|c|}
\hline & $Q_{\text {coll }}$ & $Q_{\mathrm{col} 3}$ & $Q_{\text {col4 }}$ & $Q_{\text {col5 }}$ & $Q_{\text {coltotal }}$ \\
\hline Mean $\pm \sigma$ “AMI” group & $3.27 \pm 1.79$ & $3.67 \pm 1.67$ & $1.92 \pm 1.88$ & $2.02 \pm 0.89$ & $14.17 \pm 7.07$ \\
\hline Mean $\pm \sigma$ "No-AMI" group & $6.17 \pm 3.57$ & $6.9 \pm 3.53$ & $1.63 \pm 4.66$ & $2.02 \pm 2.8$ & $22.88 \pm 11.16$ \\
\hline
\end{tabular}

TABLE 12: Simulated collateral flow rates $(\mathrm{mL} / \mathrm{min})$ in the case $(2 \mathrm{G})$ : mean values of the group "AMI" compared to those of the group "No-AMI."

\begin{tabular}{lccccc}
\hline & $Q_{\text {col1 }}$ & $Q_{\text {col3 }}$ & $Q_{\text {col } 4}$ & $Q_{\text {col5 }}$ & $Q_{\text {coltotal }}$ \\
\hline Mean $\pm \sigma$ "AMI" group & $3.02 \pm 1.58$ & $3.22 \pm 1.52$ & $2.85 \pm 1.48$ & $2.92 \pm 1.46$ & $15.05 \pm 7.61$ \\
Mean $\pm \sigma$ "No-AMI" group & $4.97 \pm 2.31$ & $5.2 \pm 2.32$ & $4.53 \pm 2.01$ & $4.48 \pm 1.93$ & $24.15 \pm 10.81$ \\
\hline
\end{tabular}

ventricular function after acute coronary occlusion. They may prevent ischemic cardiac events [26].

As found in the case $(0 G)$, in the case $(2 G)$, the collateral flows in the group "No-AMI" are higher than in the group "AMI" (Table 12). As explained in Section 3.1.4, the presence of the left grafts does not induce a significant improvement of the collateral flows.

3.2.5. Simulated Flow Rates towards the Right Capillary Area $Q_{\mathrm{RCAc}}$. These values are presented in Table 13, for the two groups of patients and for the four revascularization situations.

In all cases, the perfusion of the right capillary territory, $Q_{\mathrm{RCAc}}$, is better in the "No-AMI" group, due to higher collateral flow rates and lower microvascular resistances. As explained by Nijveldt et al. [21], despite successful recanalization of the infarct-related artery (which corresponds to the cases (1G) and (3G) in our study), in patients with AMI, perfusion of the ischemic myocardium may not be completely restored due to microvascular obstruction.

3.2.6. Simulated Total Coronary Flow Rates $Q_{t}$. The mean values of $Q_{t}$ for the two groups of patients and the four revascularization situations are given in Table 14 .

In the cases $(1 G),(2 G)$, and $(3 G)$, the total coronary perfusion, $Q_{t}$, is higher for the "No-AMI" group. This is a logical consequence of the previous results (Sections 3.2.1 to 3.2.5). The results obtained in the case $(0 \mathrm{G})$ may be related to the influence of the LAD branch; as shown in Table 9, the distal capillary resistance of this branch was found to be higher in the "No-AMI" group than in the "AMI" group.

\section{Discussion}

The range of values of the hydrodynamic data (resistances, flow rates, and so forth) obtained in our study has been discussed in detail in Maasrani et al. [1]. The agreement with the literature is good. It is hoped that such data can help the cardiologists and cardiac surgeons in decision-making process.

It can be seen from Tables 3(a), 3(b), and 10 that a decrease in blood flow occurs across the LAD graft, $\Delta Q_{\mathrm{LADg}}$, and across the LCx graft, $\Delta Q_{\mathrm{LCxg}}$, after unclamping the saphenous vein graft implanted on the occluded RCA. $\Delta Q_{\mathrm{LADg}}$ is thus defined as $\Delta Q_{\mathrm{LADg}}=Q_{\mathrm{LADg}}(2 \mathrm{G})-Q_{\mathrm{LADg}}(3 \mathrm{G})$ and $\Delta Q_{\mathrm{LCxg}}$ as $\Delta Q_{\mathrm{LCxg}}=Q_{\mathrm{LCxg}}(2 \mathrm{G})-Q_{\mathrm{LCxg}}(3 \mathrm{G})$. The mean values of these quantities are reported in Table 15, for the four groups of patients considered in this study; they are in the range of a few $\mathrm{mL} / \mathrm{min}$. These results confirm the observations we made in a previous paper [27].

In the situation $(3 \mathrm{G})$, all the grafts are operating and the role of collaterality becomes negligible (because the pressure gradient across the collateral network drops to almost zero) $[1,3,28]$. The drops in the grafts $\Delta Q_{\mathrm{LADg}}$ and $\Delta Q_{\mathrm{LCxg}}$ may thus represent the amount of collateral blood flow contributed by the left grafts in the situation (2G). It is interesting to note that these values fall exactly in the same range $(<10 \mathrm{~mL} / \mathrm{min})$ as the simulated collateral flows, $Q_{\text {coll }}$, 
TABLE 13: Simulated flow rates $(\mathrm{mL} / \mathrm{min})$ towards the right capillary area, $Q_{R C A c}$ : mean values of the group "AMI" compared to those of the group "No-AMI."

\begin{tabular}{lcccc}
\hline & $Q_{\mathrm{RCAc}}(0 \mathrm{G})$ & $Q_{\mathrm{RCAc}}(1 \mathrm{G})$ & $Q_{\mathrm{RCAc}}(2 \mathrm{G})$ & $Q_{\mathrm{RCAc}}(3 \mathrm{G})$ \\
\hline Mean $\pm \sigma$ "AMI" group & $14.12 \pm 7.07$ & $32 \pm 21.42$ & $15.07 \pm 7.63$ & $30 \pm 21$ \\
Mean $\pm \sigma$ "No-AMI" group & $22.83 \pm 11.11$ & $53.15 \pm 22.46$ & $24.17 \pm 10.83$ & $52.65 \pm 20.61$ \\
\hline
\end{tabular}

TABLE 14: Simulated total coronary flow rates ( $\mathrm{mL} / \mathrm{min}), Q_{t}$ : mean values of the group "AMI" compared to those of the group "No-AMI."

\begin{tabular}{lcccc}
\hline & $Q_{t}(0 \mathrm{G})$ & $Q_{t}(1 \mathrm{G})$ & $Q_{t}(2 \mathrm{G})$ & $Q_{t}(3 \mathrm{G})$ \\
\hline Mean $\pm \sigma$ "AMI" group & $78.87 \pm 28.35$ & $98.2 \pm 38.5$ & $88.85 \pm 34.76$ & $98.72 \pm 39.28$ \\
Mean $\pm \sigma$ "No-AMI" group & $72.9 \pm 24.54$ & $107.82 \pm 27.15$ & $93.15 \pm 22.84$ & $130.38 \pm 34.9$ \\
\hline
\end{tabular}

TABLE 15: Drops in the left grafts flow rates $(\mathrm{mL} / \mathrm{min}$ ) after unclamping the RCA graft; mean values for the four groups of patients considered in this study.

\begin{tabular}{lcccc}
\hline & “R3" group & "R1 and 2" group & "AMI” group & "No-AMI” group \\
\hline$\Delta Q_{\mathrm{LADg}}$ & $1 \pm 4.47$ & $2.4 \pm 4.72$ & $3.5 \pm 4.43$ & $0.5 \pm 4.32$ \\
$\Delta Q_{\mathrm{LCxg}}$ & $10 \pm 4.3$ & $3 \pm 10.27$ & $5 \pm 10.03$ & $7.5 \pm 7.76$ \\
\hline
\end{tabular}

$Q_{\mathrm{col} 2}, Q_{\mathrm{col} 4}$, and $Q_{\mathrm{col} 5}$, presented in Tables 5(a), 5(b), and 12 , the total collateral flow from LAD to RCA being $Q_{\text {coll }}+$ $Q_{\text {col4 }}$, and the total collateral flow from LCx to RCA being $Q_{\text {col2 }}+Q_{\text {col5 }}$ (see Figure 1). However, it appears from the measurements of Table 15 that the main decrease in flow rate occurs across the LCx graft. At the time, our model (Figure 1) does not take into account such a dissymmetry between the LAD side and the LCx side, because of the simplifying assumption that all the collateral resistances, $R_{\text {coli }}$, are the same. Improving the representation of the collateral vessels (using, e.g., some proportionality coefficients between the different $R_{\text {coli }}$ values, and/or using the data provided by Rockstroh and Brown [12]) would certainly improve the physiological relevance of the model.

\section{Conclusion}

It is demonstrated in this study that patients with a good collaterality (Rentrop Score $=3$ ) or patients without anterior myocardial infarction (No-AMI) have (i) less severe stenoses on the LMCA, (ii) lower microvascular resistances, (iii) higher grafts flow rates when the revascularization is performed, (iv) higher collateral flow rates towards the territory of the occluded artery, ( $\mathrm{v}$ ) better perfusion of this area, and (vi) better total perfusion of the heart.

The present study thus emphasizes the relevance of the hemodynamic variables for evaluation of the collateral efficiency and microvascular damages in patients with threevessel disease and total obstruction of the RCA.

\section{Conflict of Interests}

The authors confirm that there is no conflict of interests, financial or otherwise, associated with this work.

\section{Acknowledgments}

The authors want to thank Dr. J. Y. Bansard for interesting and constructive discussions about the classification of the patients.

\section{References}

[1] M. Maasrani, J. P. Verhoye, H. Corbineau, and A. Drochon, "Analog electrical model of the coronary circulation in case of multiple revascularizations," Annals of Biomedical Engineering, vol. 36, no. 7, pp. 1163-1174, 2008.

[2] M. Maasrani, I. Abouliatim, G. V. Ruggieri, H. Corbineau, J. P. Verhoye, and A. Drochon, "Simulations of fluxes in diseased coronary network using an electrical model," in Proceedings of the 19th International Conference on Electrical Machines (IEEEICEM'10), September 2010.

[3] M. Maasrani, I. Abouliatim, M. Harmouche, J. P. Verhoye, H. Corbineau, and A. Drochon, "Patients' specific simulations of coronary fluxes in case of three-vessel disease," Journal of Biomedical Science and Engineering, vol. 4, pp. 34-45, 2011.

[4] K. P. Rentrop, M. Cohen, H. Blanke, and R. A. Phillips, "Changes in collateral channel filling immediately after controlled coronary artery occlusion by an angioplasty balloon in human subjects," Journal of the American College of Cardiology, vol. 5, no. 3, pp. 587-592, 1985.

[5] J. P. Verhoye, B. De Latour, A. Drochon, and H. Corbineau, "Collateral flow reserve and right coronary occlusion: evaluation during off-pump revascularization," Interactive Cardiovascular and Thoracic Surgery, vol. 4, no. 1, pp. 23-26, 2005.

[6] R. Pietrabissa, S. Mantero, T. Marotta, and L. Menicanti, "A lumped parameter model to evaluate the fluid dynamics of different coronary bypasses," Medical Engineering and Physics, vol. 18 , no. 6 , pp. $477-484,1996$. 
[7] J. Z. Wang, B. Tie, W. Welkowitz, J. Kostis, and J. Semmlow, "Incremental network analogue model of the coronary artery," Medical and Biological Engineering and Computing, vol. 27, no. 4, pp. 416-422, 1989.

[8] J. J. Regieli, J. W. Jukema, H. M. Nathoe et al., "Coronary collaterals improve prognosis in patients with ischemic heart disease," International Journal of Cardiology, vol. 132, no. 2, pp. 257-262, 2009.

[9] P. G. Steg, A. Kerner, G. B. J. Mancini et al., "Impact of collateral flow to the occluded infarct-related artery on clinical outcomes in patients with recent myocardial infarction: a report from the randomized occluded artery trial," Circulation, vol. 121, no. 25, pp. 2724-2732, 2010.

[10] M. Ishihara, H. Sato, H. Tateishi et al., "Usefulness of coronary wedge pressure in evaluating coronary collateral circulation in anterior wall acute myocardial infarction," American Journal of Cardiology, vol. 75, no. 5, pp. 394-396, 1995.

[11] G. S. Werner, M. Ferrari, S. Heinke et al., "Angiographic assessment of collateral connections in comparison with invasively determined collateral function in chronic coronary occlusions," Circulation, vol. 107, no. 15, pp. 1972-1977, 2003.

[12] J. Rockstroh and B. G. Brown, "Coronary collateral size, flow capacity, and growth estimates from the angiogram in patients with obstructive coronary disease," Circulation, vol. 105, no. 2, pp. 168-173, 2002.

[13] S. A. J. Chamuleau, M. Siebes, M. Meuwissen, K. T. Koch, J. A. E. Spaan, and J. J. Piek, "Association between coronary lesion severity and distal microvascular resistance in patients with coronary artery disease," American Journal of Physiology: Heart and Circulation Physiology, vol. 285, no. 5, pp. H2194-H2200, 2003.

[14] S. C. Smith, R. Gorlin, M. V. Herman, W. J. Taylor, and J. J. Collins, "Myocardial blood flow in man: effects of coronary collateral circulation and coronary artery bypass surgery," Journal of Clinical Investigation, vol. 51, no. 10, pp. 2556-2565, 1972.

[15] C. Spies, O. Mohrs, J. Madison, A. Fach, B. Nowak, and T. Voigtländer, "Limited flow reserve in non-obstructed bypass grafts supplying infarcted myocardium: implications for cardiovascular magnetic resonance imaging protocols," Journal of Cardiovascular Magnetic Resonance, vol. 8, no. 2, pp. 373-379, 2006.

[16] T. Hirotani, T. Kameda, S. Shirota, and Y. Nakao, "An evaluation of the intraoperative transit time measurements of coronary bypass flow," European Journal of Cardio-Thoracic Surgery, vol. 19, no. 6, pp. 848-852, 2001.

[17] D. Glineur, A. Poncelet, G. E. Khoury et al., "Fractional flow reserve of pedicled internal thoracic artery and saphenous vein grafts 6 months after bypass surgery," European Journal of Cardio-Thoracic Surgery, vol. 31, no. 3, pp. 376-381, 2007.

[18] N. Spyrou, M. A. Khan, S. D. Rosen et al., "Persistent but reversible coronary microvascular dysfunction after bypass grafting," American Journal of Physiology: Heart and Circulation Physiology, vol. 279, no. 6, pp. H2634-H2640, 2000.

[19] S. Miyamoto, M. Fujita, and S. Sasayama, "Bidirectional function of coronary collateral channels in humans," International Journal of Cardiology, vol. 75, no. 2-3, pp. 249-252, 2000.

[20] P. Elsman, A. W. J. Van't Hof, M. J. De Boer et al., "Role of collateral circulation in the acute phase of ST-segmentelevation myocardial infarction treated with primary coronary intervention," European Heart Journal, vol. 25, no. 10, pp. 854$858,2004$.
[21] R. Nijveldt, A. M. Beek, A. Hirsch et al., "Functional recovery after acute myocardial infarction. Comparison between angiography, electrocardiography, and cardiovascular magnetic resonance measures of microvascular injury," Journal of the American College of Cardiology, vol. 52, no. 3, pp. 181-189, 2008.

[22] D. Bexell, R. Setser, P. Schoenhagen et al., "Influence of coronary artery stenosis severity and coronary collateralization on extent of chronic myocardial scar: insights from quantitative coronary angiography and delayed-enhancement MRI," The Open Cardiovascular Medicine Journal, vol. 2, pp. 79-86, 2008.

[23] B. E. P. M. Claessen, M. Bax, R. Delewi, M. Meuwissen, J. P. S. Henriques, and J. J. Piek, "The Doppler flow wire in acute myocardial infarction," Heart, vol. 96, no. 8, pp. 631635, 2010.

[24] R. A. M. Van Liebergen, J. J. Piek, K. T. Koch, R. J. De Winter, C. E. Schotborgh, and K. I. Lie, "Quantification of collateral flow in humans: a comparison of angiographic, electrocardiographic and hemodynamic variables," Journal of the American College of Cardiology, vol. 33, no. 3, pp. 670-677, 1999.

[25] D. C. Levin, "Pathways and functional significance of the coronary collateral circulation," Circulation, vol. 50, no. 4, pp. 831-837, 1974.

[26] J. Koerselman, Y. Van der Graaf, P. P. T. De Jaegere, and D. E. Grobbee, "Coronary collaterals: an important and underexposed aspect of coronary artery disease," Circulation, vol. 107, no. 19, pp. 2507-2511, 2003.

[27] J. P. Verhoye, I. Abouliatim, A. Drochon et al., "Collateral blood flow between left coronary artery bypass grafts and chronically occluded right coronary circulation in patients with triple vessel disease. Observations during complete revascularisation of beating hearts," European Journal of CardioThoracic Surgery, vol. 31, no. 1, pp. 49-54, 2007.

[28] M. Fujita and K. Tambara, "Recent insights into human coronary collateral development," Heart, vol. 90, no. 3, pp. 246-250, 2004. 


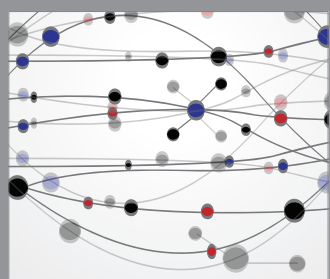

The Scientific World Journal
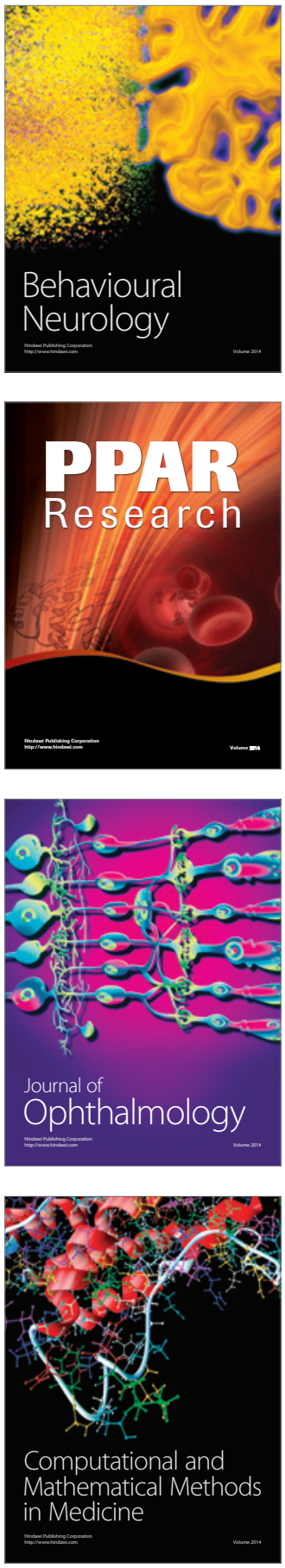

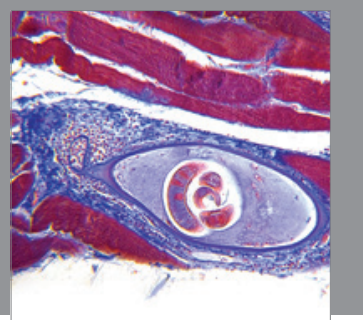

Gastroenterology

Research and Practice
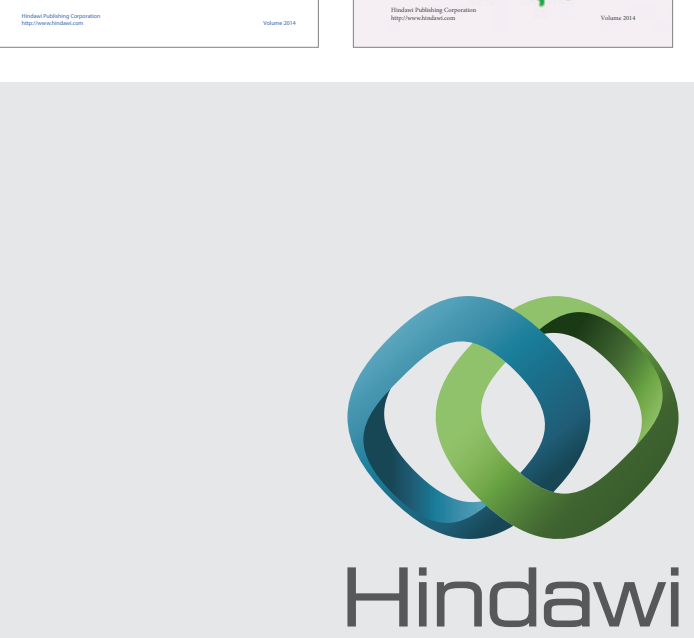

Submit your manuscripts at

http://www.hindawi.com
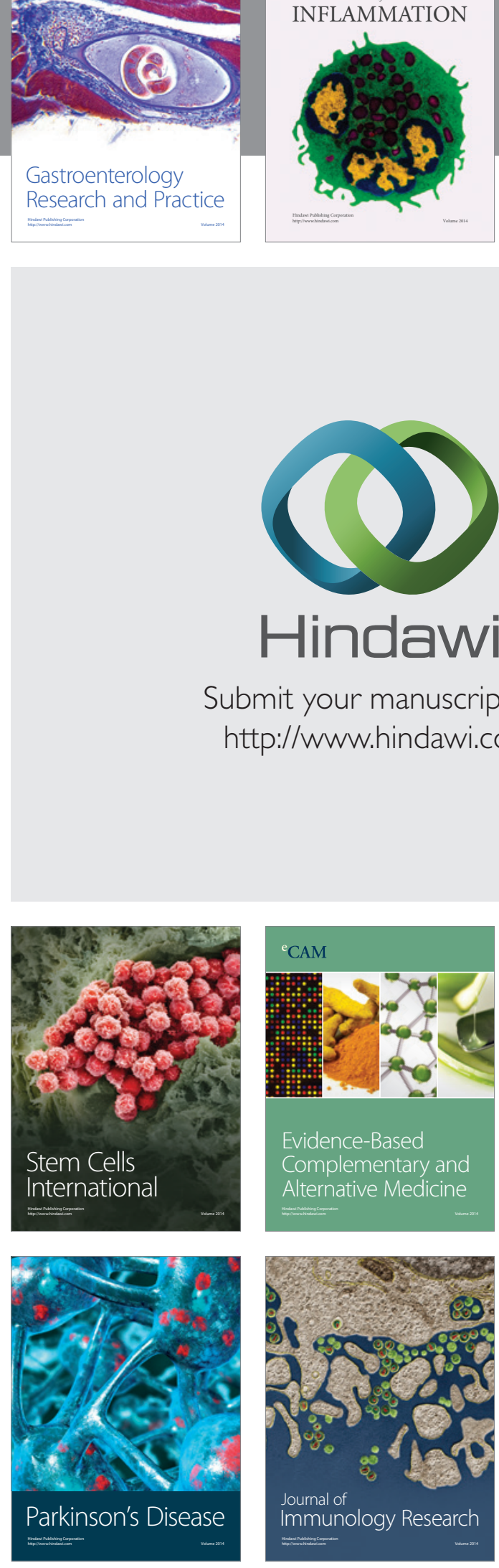

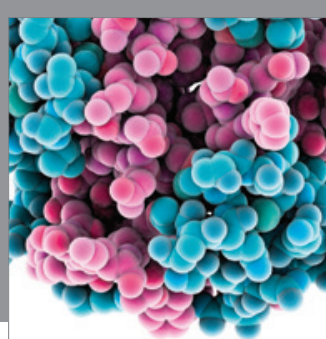

Diabetes Research
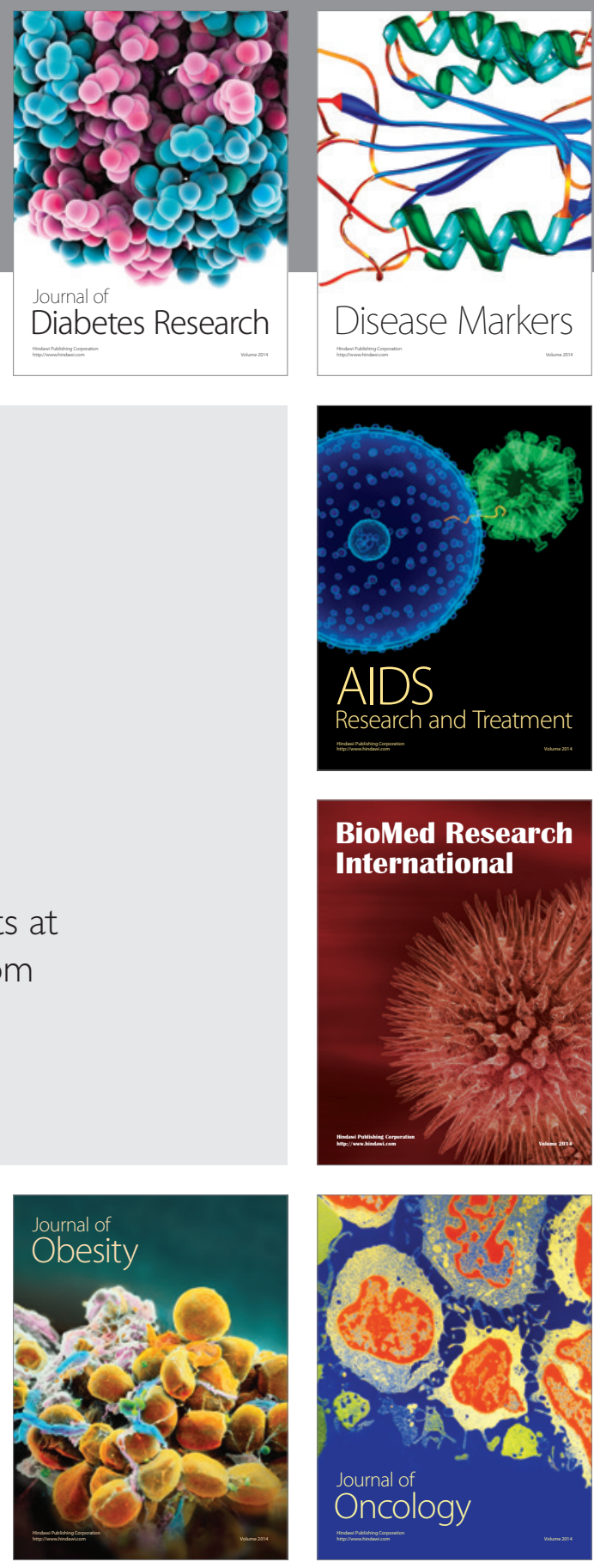

Disease Markers

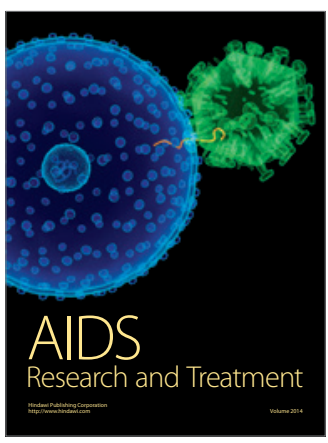

BioMed Research

International
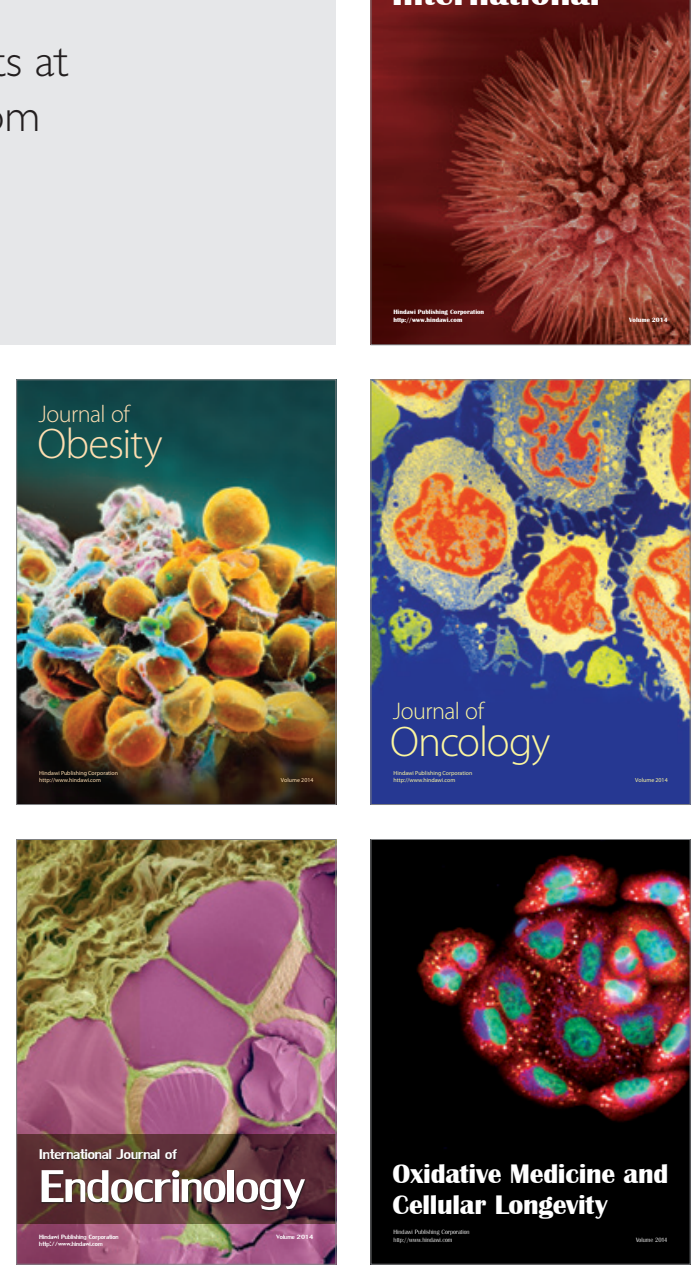